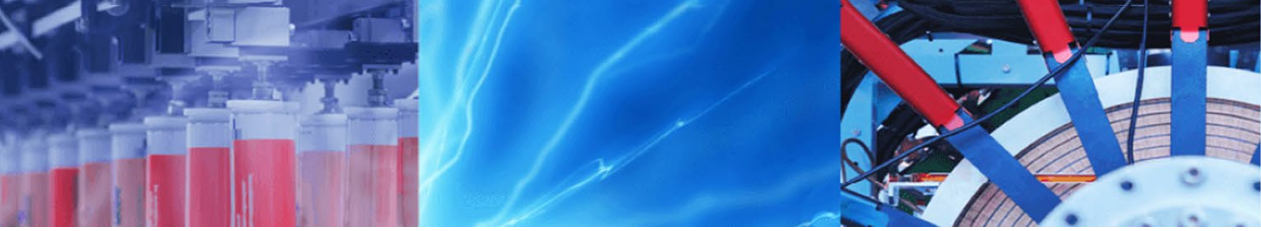

Research Article

\title{
Lithium lubricating greases containing carbon base nano-additives: preparation and comprehensive properties evaluation
}

\author{
Mehran Sadeghalvaad ${ }^{1,4}$ (D) Erfan Dabiri $^{2,4} \cdot$ Pooneh Afsharimoghadam ${ }^{3,4}$
}

(c) Springer Nature Switzerland AG 2019

\begin{abstract}
The aim of this research is to investigate the enhancement of lubricating and sealant properties, increase of the life time, and reduce of wear traces for lubricants and sealant greases. For this purpose, carbon dot (C-dot) nanoparticles (NPs) were synthesized successfully to add to the lithium based grease in $0.1,0.2,0.4,0.6,0.8$ and $1 \mathrm{wt} \%$. To better understand the effect of NPs on the properties of lithium based grease, carbon nanofiber (CNF) and Nano-Fullerene (C60) were also used in the mentioned weight percentages to add to the lithium based. NPs were well dispersed in the phase of base grease by the use of ultra-sonication. Variety of tests were done on the lithium base grease and all of the fabricated nanogreases and their results were then compared with each other. Using NPs did not remain any corrosive tracks for all of the nano-greases and caused the improvement in all their properties. Prepared nanogreases were also resistant to fuel, water, and aqueous alcohol in a specific period of time. CNFs with weight percentages in the range of $0.4-0.8$ showed to be the optimum NPs content to be added to the lithium based grease in terms of improved properties.
\end{abstract}

Keywords Nano-grease · Lithium soap · Carbon nanofibers · Fullerene · Carbon nano-dots

\section{Introduction}

When a mechanical system starts to operate, it will be in the equilibrium condition after some hours and the grease bulk is used to cover abrasive surfaces, ball bearings, and rings [1]. Besides the reduction and control of the friction, using grease lubricants will contribute to the decrease of abrasion rate, absorb of surface pollutants, sealing and force transfer purposes, and preventing the pieces to become too hot and also corroded [2-5]. Oil viscosity is an important factor in the grease while do not have much effect on the thickening of the grease. In fact, concentration of the grease depends on the kind and amount of the thickener. Thickener will endow a coherency to the grease and it is usually assumed as a sponge in which holds the base oil [2]. Greases are categorized with respect to type of the base oil (mineral, synthetic, and vegetable) and type of the thickener (metal soaps, polymers, and minerals) [3, 6]. Commercialized greases available in the market consist of mineral based oil or Polyalphaolefin and metal soaps like lithium, calcium, and aluminum [7]. Soap particles are metal salts of fatty acids which give a fibrous structure to the grease. Tying the fibrous particles of soap with each other will make the structure of the grease more concentrated [8]. Nanotechnology plays a prominent role in different applications [9-15]. Recently, the use of NPs, as additives for enhancing the lubrication and conduction of the base grease has attracted many attentions. NPs have

Electronic supplementary material The online version of this article (https://doi.org/10.1007/s42452-019-0289-7) contains supplementary material, which is available to authorized users.

Mehran Sadeghalvaad, m.sadeghalvaad@gmail.com | ${ }^{1}$ Nano Chemical Engineering Department, Faculty of Advanced Technologies, Shiraz University, Shiraz, Iran. ${ }^{2}$ Department of Gas Engineering, Ahwaz Faculty of Petroleum, Petroleum University of Technology, Ahwaz, Iran. ${ }^{3}$ Department of Earth Sciences, College of Science, Shiraz University, Shiraz, Iran. ${ }^{4}$ Nano Chemical Engineering Department, Radin Faradid Petrosanat Co, Fars Science and Technology Park, Shiraz, Iran. 
high surface to volume ratio and accordingly, will endow desirable physical properties to the base grease [16]. High energy of free surfaces in NPs results in the formation of agglomeration [17]. To prevent this phenomenon, methods of preparation for the nano-grease and mixing of NPs are important. Dispersion methods of NPs includes direct mixing (by the use of mechanical mixer), three roll mill, and dispersion with ultra-sonication. Nanoscale additives of the grease are often categorized in three groups of inorganic, carbon base, and hybrid (surface capped) NPs [18].

Shape and structure of carbon based NPs play an outstanding role in the selection of NPs and affect the lubrication behavior of greases. NPs improve anti-wearing and anti-frictional properties of greases because of three reasons: (1) the performance of spherical NPs on the contact surface has the same affection as the micro bearing and therefore, the friction coefficient is reduced. This phenomenon is called the ball effect. (2) tribochemical reaction effect and the creation of a protective layer on the contact surface, and (3) repair effect by covering the micro porosities and the defective surfaces with NPs at the wear surface $[12,13]$.

Fabricated nano-greases are applicable in many industries like energy generation, transportation, cooling, chemical production, industrial valves, and bearings $[1,14]$. In recent years, lithium grease has shown good performance in the lubricating of mechanical equipment, lowering the wear and friction, increasing the lifetime of mechanical equipment, and reducing the energy consumption. This grease is also used broadly in automotive, aerospace, shipbuilding, and machinery industries $[19,20]$.

Bartz and coworkers were concluded that adding of solid lubricants to the mineral oil could have anti-wearing effects. This effect is dependent on other additives existing in the oil, hardness of the particles, and also the size of solid lubricants [21]. To improve lubrication properties of the lithium based grease, Cheng et al. dispersed Tin (Sn) NPs in the base grease. Anti-wear and anti-friction properties of fabricated nano-greases in different size and weight percentages of NPs were measured. Their results showed that the addition of Sn NPs had an effective impact on the reduction of wear and friction coefficient [20]. Utilizing gold and copper NPs in the lubricants were also studied and their anti-wear and anti-friction properties were discussed $[22,23]$. Studies on the addition of multi-layer graphene, as an additive to the lithium based grease were done by Fan and his colleagues and they showed that load bearing of the base grease was improved [24]. High efficiency performance of lubricants containing graphene NPs can be the result of their tiny size and thin flatty structure leading to the reduction of shear stress and collision prevention of metal interface. Furthermore, graphene surfaces could easily inter the structure of oil and form a protective layer for preventing the straight collision of surfaces and then improve their wearing properties [25]. Graphite NPs were also studied as an additive to the industrial oil with the cinematic viscosity of 220 cSt [26]. While the results of the research done by Chen et al. showed that adding of titanium dioxide $\left(\mathrm{TiO}_{2}\right)$ and silicon dioxide $\left(\mathrm{SiO}_{2}\right)$ to the lithium based grease did not improve the load bearing capacity, the ability of improving the load bearing capacity was referred to a cleverly combination selection of NPs and type of the base grease [27]. Wu et al. investigated the effect of $\mathrm{CuO}$ and $\mathrm{TiO}_{2}$ nano-additives on the lubricating and anti-wearing behavior of the base oil. Their results showed that using $\mathrm{CuO}$ nano-additives had better performance in the friction reduction of the oil than that of using $\mathrm{TiO}_{2} \mathrm{NPs}$ [28]. Hybrid nanolubricant composed of a flowable oil or grease with a multi-component nanoparticle was also studied in the literature [29]. Using the combination of $\mathrm{Al}_{2} \mathrm{O}_{3}$ and $\mathrm{ZnO}$ nano-additives were also investigated and it was concluded that the friction between flat surfaces were decreased. Probing into the wearing of flat surfaces showed that used NPs had the same behavior as the wearing particles and accordingly, the wear rate at the surfaces could be better detected by harder particles [30]. Zinc Aluminate $\left(\mathrm{ZnAl}_{2} \mathrm{O}_{4}\right)$ and Gahnite NPs increased the anti-wear and anti-friction properties of the oil with $0.1 \mathrm{wt} \%$ of NPs [31]. Wei and coworkers had some researches on the tribological properties of $\mathrm{Al}_{2} \mathrm{O}_{3}-\mathrm{TiO}_{2}$ nanocomposite by friction and wear tests. They showed that applying the mentioned NPs in the structure of oil had better anti-wear and anti-friction properties than the use of $\mathrm{Al}_{2} \mathrm{O}_{3}$ and $\mathrm{TiO}_{2}$, separately [32]. Mohamed et al. [2] studied the effect of adding Carbon nanotubes (CNTs) in different weight percentages on the tribological properties of lithium based grease. Younes and coworkers probed into the effect of adding three-dimensional carbon nanostructures (C60, CNT and SWNT) to the Polyolefin oil based grease and their results indicated that the mentioned carbon NPs did not form a stable structure. They reported the weak Van der Waals intermolecular force for the reason of the mentioned phenomenon. [7]. Nano-lubricants containing fullerene NPs in the refrigeration mineral oil were also synthesized and their performances were evaluated [33].

In this research, three carbon based NPs with different shapes and structures including CNF, C60 and C-dot in 6 different contents were used to disperse in the lithium based grease. From the mentioned NPs, C-dots were synthesized, separately. Then, anti-wear, anti-friction, viscosity, penetration, dropping point, corrosion, flash point, fire point, thermal stability, moisture resistance, extreme pressure properties, along with resistance to different solvents for the fabricated nano-greases were measured and evaluated in accordance with the standard methods 
available in the literature. These properties were compared with those of the base grease. By analyzing and comparing the results, the best Nano-additive with optimum weight percent was proposed to be added to the lithium grease to be utilized in the lubrication of industrial valves.

\section{Experimental}

\subsection{Materials}

In this work, two stages method was implemented to prepare the nano-greases. The considered commercialized base grease (with the model of SAV733) was prepared with the mentioned characteristics in Table A1 (from Appendix A). This lithium based grease had proper thermal and water resistance along with the mechanical stability. Additives of Carbon Nanofiber (CNF), Nano-Fullerene (C60), and Carbon Nano-dot (C-dot) with different weight percentages (0.5, 1,2 , and 3 ) were used to be added to the lithium grease. It should be noted that carbon nano-dots were not available in the market and accordingly, this NP was synthesized in this research by the hydrothermal method. CNFs and C60 NPs were purchased from Sigma-Aldrich Company. In addition, two mentioned NPs were stable in the structure of the grease and did not need to be modified on surface. Because of the high rates of viscosity for the base fluid, ball mill method was utilized to disperse NPs in the base fluid and for this purpose, a ball mill (model of 100 Retche PM) was used. Characteristics of the mentioned device for preparation of Nano-greases are shown in the Table A2.

\subsection{Synthesis of C-dot NPs}

According to the studies and researches carried out and also availability of necessary equipment, hydrothermal method was used to synthesize carbon Nano-dot. Table A3 shows required chemical materials for the synthesis of carbon Nano-dot. $3 \mathrm{ml}$ of ethanol was putted inside an autoclave (model of Kavoosh Mega, made up of stainless steel and with the volume capacity of $5 \mathrm{ml}$ containing 4 and $23 \mathrm{ml}$ of $\mathrm{H}_{2} \mathrm{O}_{2}$ (30 wt\%) and deionized water, respectively). Hydrothermal operation was done on the created solution at $180^{\circ} \mathrm{C}$ and for the time duration of $12 \mathrm{~h}$ to obtain a yellow fluid containing dispersed particles of carbon nano-dot. After the separation of carbon nano-dots by a dialysis tube in the distilled water, they were putted under the oven at $60^{\circ} \mathrm{C}$ to become dried and giving us $5 \mathrm{mg}$ of carbon nano-dot powder. This synthesis method was used by $\mathrm{Hu}$ et al. [34] to investigate the Photoluminescence property.

\subsection{Preparation of nano-greases}

For the preparation of nano-greases, different weight percentages of $\mathrm{C} 60, \mathrm{CNF}$, and $\mathrm{C}$-dot were used. With respect to the fact that nano-size of these materials are more effective in the structure of grease than the micrometer particles, nano-greases were prepared with the weight percentages of $0.1,0.2,0.4,0.6,0.8$, and 1 . Used NPs were well distributed in the commercialized lithium base grease for $15 \mathrm{~min}$ and at $30^{\circ} \mathrm{C}$. Properties of the base grease (SAV 733) which was used in this work are shown in the Table A4.

\subsection{Test methods for the evaluation of nano-greases}

\subsubsection{Viscosity}

Viscosity is one of the parameters which plays a prominent role in the process of lubrication. In the present work, a rotating viscometer (model of Brookfield DV-II+Pro), along with a spindle and an adaptor (model of UL Adaptor $316 \mathrm{~s} / \mathrm{s}$ ) were used to measure this property.

\subsubsection{Permeability}

After preparing the nano-greases, they were tested to investigate their permeability by the cone penetration test with the standard of ASTM -D217.

\subsubsection{Dropping point}

Dropping point is an indicator of the heat resistance of the grease and is the lowest temperature in which the oil can flow and the phase of grease changes from semi-solid to liquid [35]. This temperature was determined by the standard method of ASTM D566.

\subsubsection{Corrosion}

Standard test method of ASTM D4048 was used to determine the corrosion of the copper strip, which was covered by a layer of grease. Results of this test are important in predicting the situations in which greased pieces having copper or copper alloy are imposed to the chemical corrosion condition. These corrosions can led to the early failure in pieces like bearings and should be avoided. In this standard method, corrosive sample will be analyzed with respect to the appearance of test blade (copper piece) and its comparison with one of the standard corroded states. 


\subsubsection{Flash and fire points}

Measurement of the flash point was done by a Cleveland Open Cup Flash Point tester (Stanhope-Setaand Company, UK) with the standard method of ASTM D92. Experiments were repeated three times at the same conditions to ensure the correctness of the results of this test. The general procedure for determination of the flash point is completely the same as the fire point and standard test method of ASTM D92 was already used to measure the fire points of greases.

\subsubsection{Evaporation loss}

In this test, the effect of temperature on the lubricant without the presence of oxygen is investigated. Probing into the evaporation in greases were done in this study by the standard method of ASTM D972. Reduction or mass decrease of the grease by the evaporation was obtained by this test method for the applications in which evaporation in greases are an important factor. Mass reduction rate by the evaporation was determined in the temperature range of $100-150^{\circ} \mathrm{C}$.

\subsubsection{Humidity resistance}

The ability of water to wash greases was obtained by the standard method of ASTM D1264. The purpose of conducting this standard test method is to determine the stability of grease lubricants on the bearings against washing by the water (water washout characteristic). This test was repeated two times to decrease the errors in results.

\subsubsection{Extreme-pressure (EP) properties}

Standard test methods of ASTM D2596 and DIN 51805 were implemented to differentiate of grease lubricants into the three categories for EP properties of low, medium, and high. The purpose of this test is to measure the property of loading resistance of greases with respect to the parameters of loading-abrasion characteristic and the point of its welding with the four balls device for EP measurement.

\subsubsection{Resistance of nano-greases to fuel, water, and aqueous alcohol}

DEF Stan 91-6/4 test method was implemented to evaluate the resistance of all nano-greases to some solvents at specific conditions. As fabricated nano-greases are considered to be utilized and applied in industrial valves, the results of this section is important to determine if these nano-greases can endure harsh operating conditions in such applications.

\section{Results and discussion}

\subsection{Rheological, Physical, and Tribological Properties of nano-greases}

\subsubsection{Viscosity test}

Adjacent fluid layers are responsible for viscous friction and viscosity of nanogreases can determine the shearing
Fig. 1 The effect of adding CNFs to the base grease on their shear stress

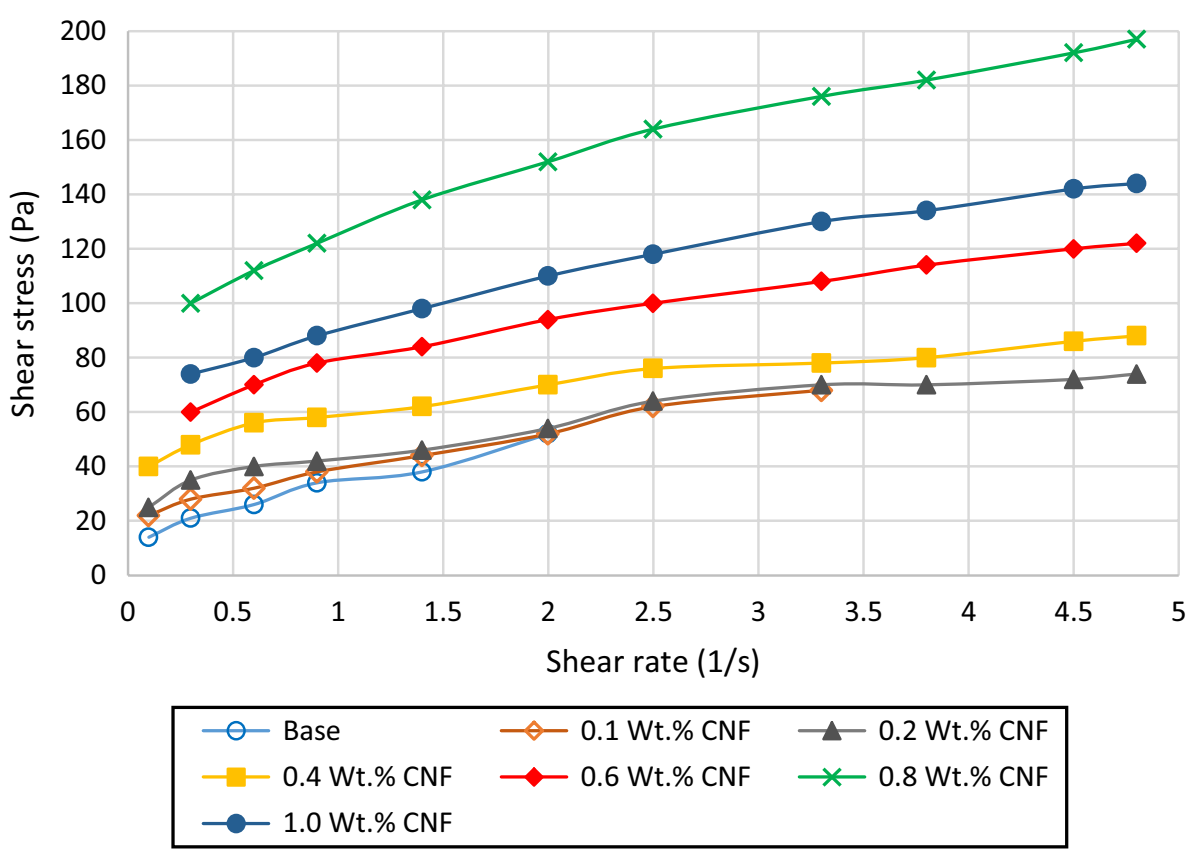


Fig. 2 The effect of adding CNFs to the base grease on their apparent viscosity

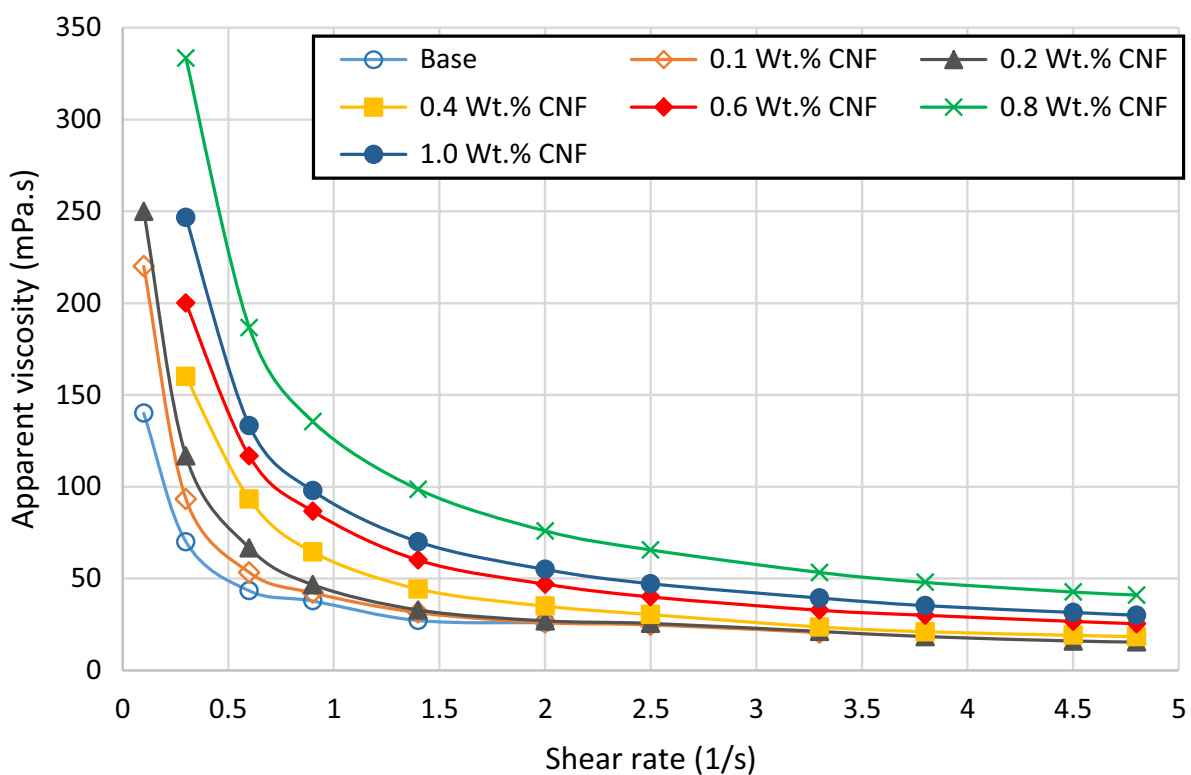

force between these layers [36]. In other words, load carrying capacity and viscous friction of the nanogrease can be determined by its viscosity [37]. Parameters like shear stress and apparent viscosity are determined by the viscosity test. Figures 1 and 2 show the results of these parameters for the base grease and modified ones by CNFs (at $0.1,0.2,0.4,0.6,0.8$, and $1.0 \mathrm{wt} \%$ ). It should be noted that experiments were repeated for three time at the same conditions to reduce the experiment errors and average values were considered in the figure. Results indicated that raising the shear rate contribute to the increase of the shear stress while reduce the viscosity of the grease. It is obvious in this figure (and also Figs. 3 and 5) that the shear stress and the shear rate are linearly dependent and this indicates the Newtonian behavior of the prepared nano-greases. It was observed that the shear stress and apparent viscosity of the nano-grease containing $0.8 \mathrm{wt} \%$ of CNFs are higher than those of the other nanogreases and also were more stable with respect to the base grease in all shear stresses. In addition, these parameters were increased by raising the content of CNFs in the Nano-grease. Experiments were conducted at the same conditions and showed the thixotropic behavior for fabricated Nano-grease and
Fig. 3 The effect of adding C60 NPs to the base grease on their shear stress

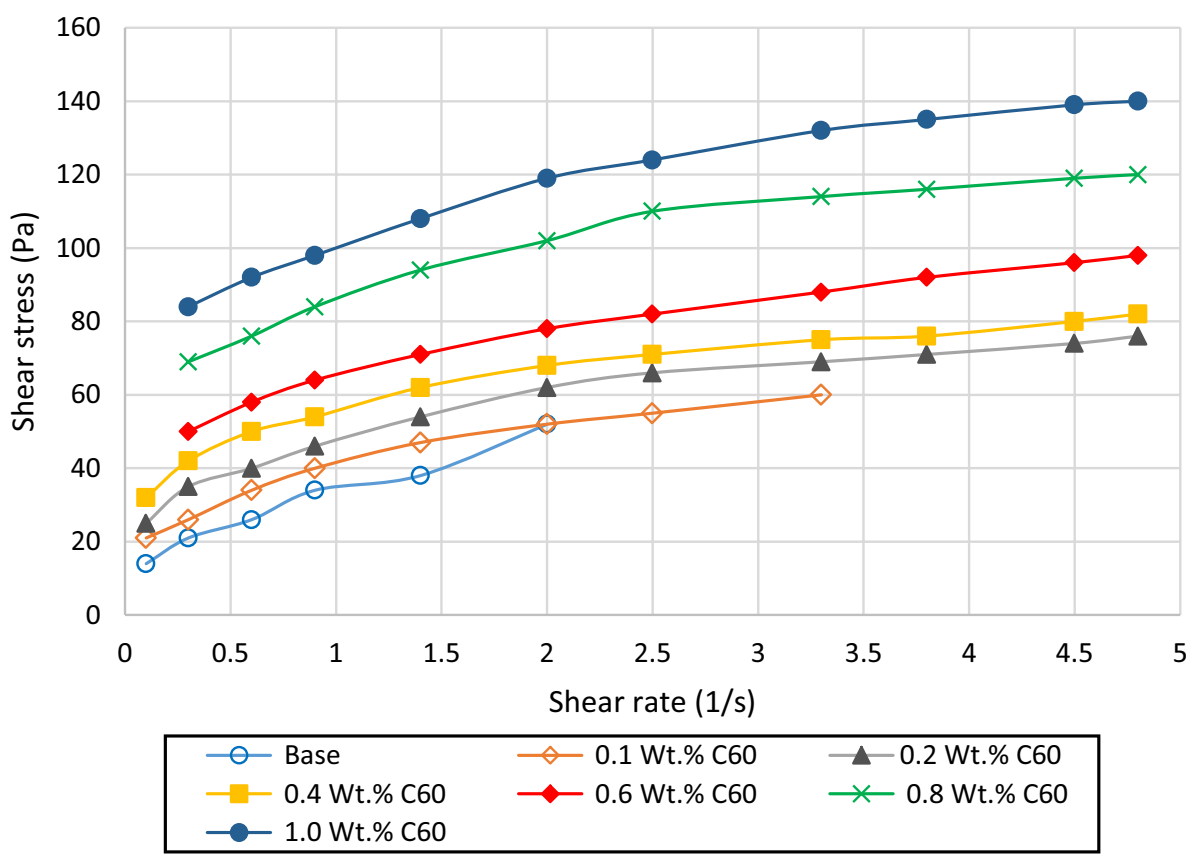

SN Applied Sciences 
accordingly, shear thinning behavior can be observed for the Nano-greases. Viscosity of these fluids will be decreased by raising the shear rate. Starch, soup, pigment, grease, and etc. are some of these materials with the mentioned behavior. Nanoparticles will act as the disturbance of the fluid and the hydrodynamic interactions between them around one particle and also interact with the other ones at higher contents is the main reason for decrease of apparent viscosity with increasing the shear rate.
Figures 3 and 4 illustrate also the shear stress and apparent viscosity for the base grease and modified grease with Nano-Fulleren (C60) in weight percentage of $0.1,0.2,0.4,0.6,0.8$, and 1 . Shear stress and apparent viscosity were increased and decreased, respectively by further raising the shear rate. It can be detected from the figure that shear stress and apparent viscosity of the nanogrease containing $1 \mathrm{wt} \%$ of $\mathrm{C} 60$ are far higher than those of the base grease at all studied shear stresses. In addition, further incensing the content of $\mathrm{C} 60$ caused these
Fig. 4 The effect of adding C60 NPs to the base grease on their apparent viscosity
Fig. 5 The effect of adding C-dot NPs to the base grease on their shear stress
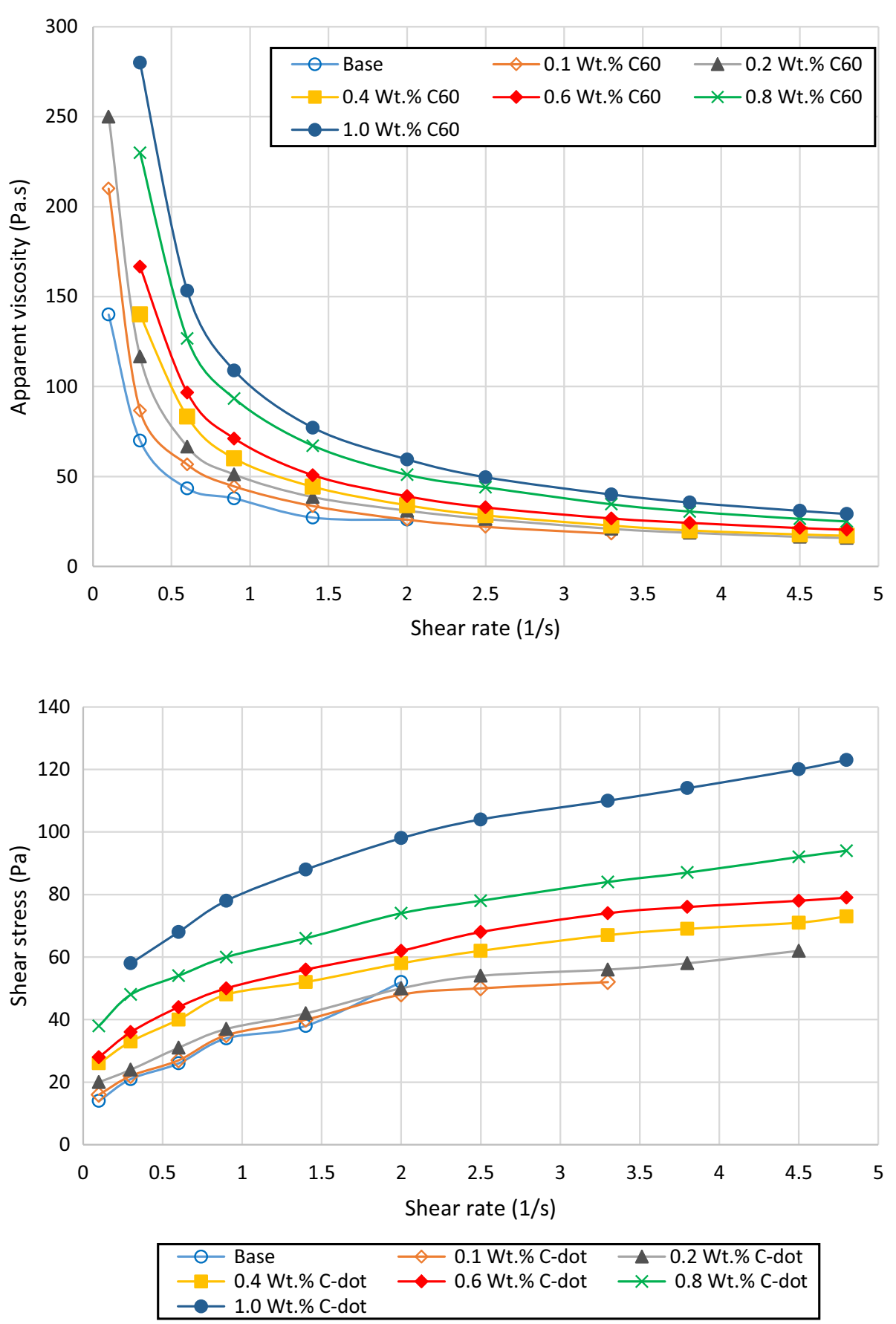
Fig. 6 The effect of adding C-dot NPs to the base grease on their apparent viscosity

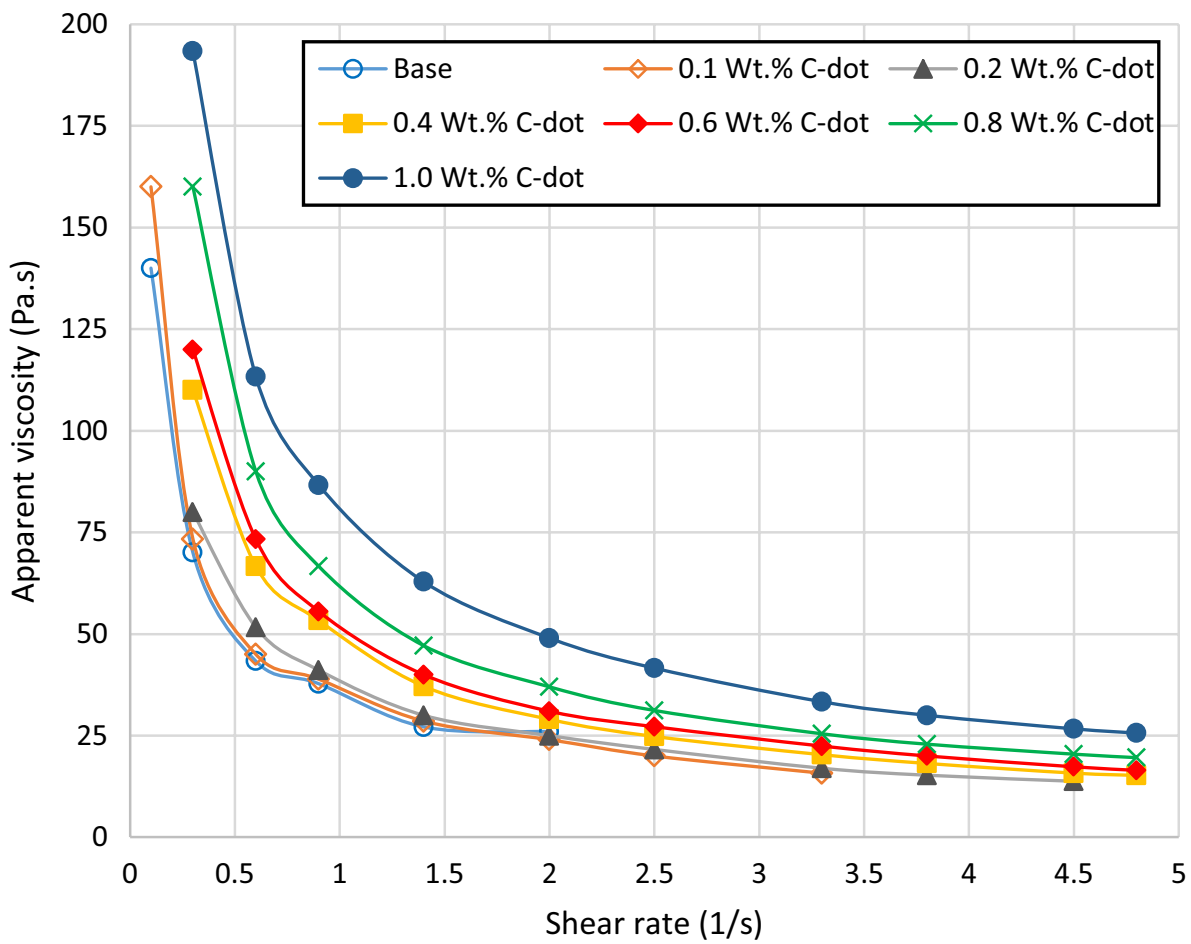

parameters to be increased. Shear stress and apparent viscosity versus the shear rate for the base grease and modified nano-greases with C-dot NPs (at 0.1, 0.2, 0.4, 0.6, 0.8, and $1 \mathrm{wt} \%$ ) are shown in Figs. 5 and 6 , respectively. The same results for the apparent viscosity and shear stress of nano-greases containing C60 NPs were also observed for the modified grease with C-dot nano-additives. In general, results indicated that all fabricated nano-greases showed thixothropic behavior in the form of shear thinning. Furthermore, shear stress and apparent viscosity with respect to the shear rates for modified nano-greases with CNFs is more than those for the nano-grease with $\mathrm{C} 60 \mathrm{NPs}$. While these parameters for the nano-grease containing $\mathrm{C} 60$ were found to be more than those for the C-dot nano-grease. As a result, CNFs with $0.8 \mathrm{wt} \%$ showed the best amount of NP to be added to the base grease in terms of increased viscosity and shear stability with respect to those of nanogreases with the same contents of $\mathrm{C} 60$ and C-dot. All prepared nano-greases were found to have Newtonian behavior and addition of NPs to the base grease caused their shear stress and apparent viscosity to be increased and decreased, respectively versus the shear rate. This behavior indicates the anti-wear and anti-friction properties of used NPs leading to have better lubrication in the considered applications, as industrial valves.

In general, viscosity of greases increase with the addition of nano-additives and this can be attributed to agglomeration of nanoparticles in the nano-grease, preventing the easy movement of adjacent oil layers [38].

\subsubsection{Penetration test}

Penetration rate of nano-greases in different weight percentages and two states of unworked and worked sample are shown in Figs. 7 and 8, correspondingly. Results were obtained by repeating the experiment by three times and their standard errors can be seen in the mentioned figures. Adding up of Nano-fulleren (C-60) and CNFs to the grease caused their penetration rates to be decreased by raising their weight percentages. This can be due to the fact that fibrous structure of the nano-greases prevents the easy penetration from these structures. With respect to the fact that CNFs have interwoven and fibrous structure, the gas will be prevented from passing this structure because of the increase in mean free path of the gas flow in the grease. Decrease of the grease penetration by raising the Nano-fullerene and CNFs content means their increase of consistency and therefore, mentioned NPs have thickening effect on the grease. Moreover, good dispersion and large specific surface area of CNFs caused them to have better thickening effect and the basic texture of greases doesn't change considerably. 0.6 wt $\%$ of CNFs was found to be the optimum amount of NPs that can be considered to be added to the base grease in terms of reduced penetration rates. For the use of 0.8 and $1 \mathrm{wt} \%$ of CNFs, no significant changes was observed for the penetration reduction and permeability values were about the same in the mentioned two cases (legends of the figures are regarded to the nano-grease containing such nanoparticle). 
Fig. 7 Penetration of nanogreases in the unworked state

Fig. 8 Penetration of nanogreases in the worked state

Fig. 9 The effect of adding NPs to the base grease on their dropping points
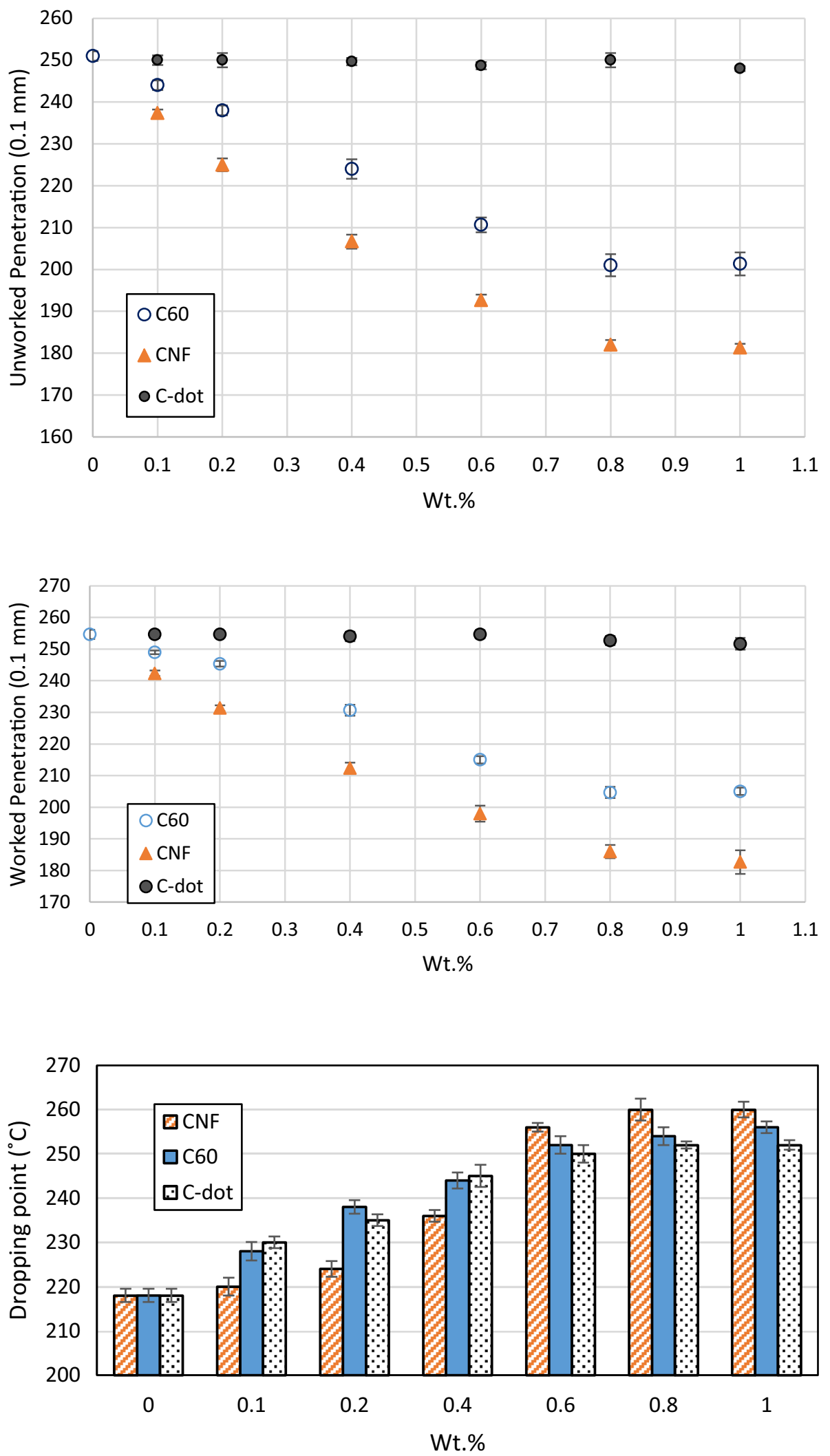


\subsubsection{Dropping point}

Results of dropping point for nano-greases with different contents are shown in Fig. 9. These results were obtained from the average values of conducted experiments with three times repeatability. Raising the weight percentages of NPs leaded to the increase of the dropping point for the prepared nano-greases. This could be a merit for nano-greases because increasing the dropping point can cause them to be separated from the oil at higher temperatures and as a result, kept their structures at high temperatures. On the other hand, better high temperature performance of the prepared nanogreases as well as their structural stability are the results of presence of NPs. In addition, modified nanogreases containing 0.8 and $1 \mathrm{wt} \%$ of CNFs devoted the largest increase rates in the dropping point with respect to those of other nano-greases and as a result, had better high temperature performance and stability. (Legend of the figure is regarded to the nano-grease containing such nanoparticle).

\subsubsection{Corrosion}

Results of copper corrosion test for all the studied nanogreases in different weight percentages of NPs indicate that they had little color changes in different corrosion rates. These color changes are the same as the copper strip which was polished recently and in some cases, the color was inclined to the bright orange and accordingly, the condition of copper strip can be categorized in the classification of 1a (according to the standard of ASTM D4048(. In this test method, the corrosion rate in different cases can show itself by the color change from almost
Fig. 10 The effect of adding NPs to the base grease on their flash points

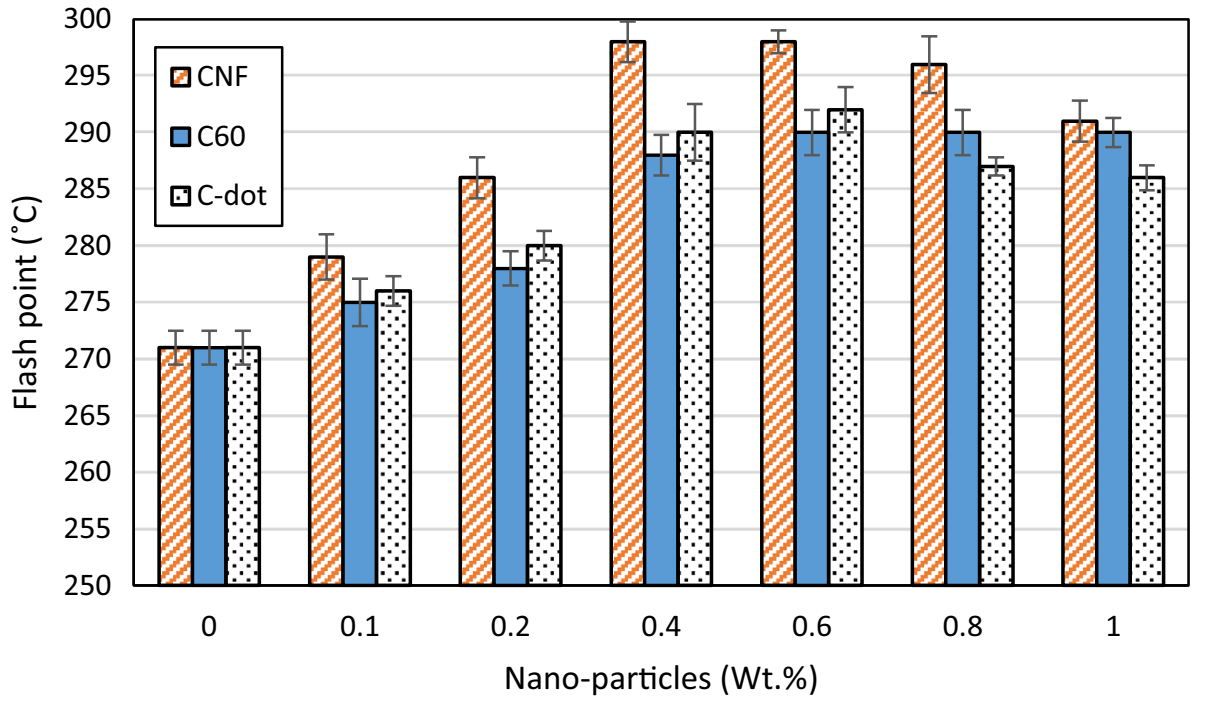

Fig. 11 The effect of adding NPs to the base grease on their fire points

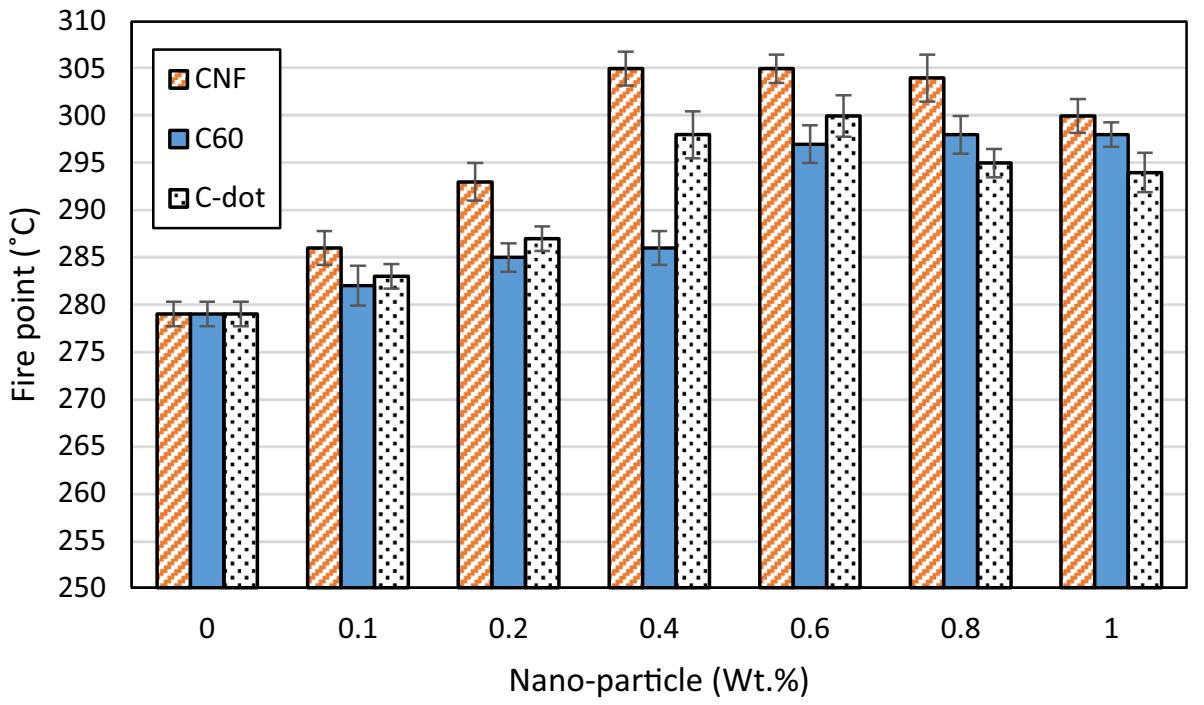

SN Applied Sciences A SPRINGER NATURE journal 
without color to the black and numbers of 1-4 indicate the color change resulting from the corrosion. The importance of this test for prepared nanogreases is due to the application of these nanogreases in industrial valves and all the nanogreases were resistant to become corroded in the specified condition, according to the standard test method.

\subsubsection{Flash and fire points}

Results of the flash point test is dependent on the design of considered device, how to use it, and conditions of the test. Figures 10 and 11 illustrate the results of measured flash and fire points, respectively for the base grease and modified greases with NPs. As it can be seen in these figures, raising the weight percentages of NPs led to the increase of their flash points. This increase was more sensible for the modified grease with CNFs. In other words, CNFs showed to give better performance to the grease in terms of the flash point with respect to the use of other NPs in the grease. The increase in flash point of the nanogrease containing $0.4 \mathrm{wt} \%$ of CNFs was found to be the highest and further raising the content of the NP caused the trend of changing flash point to be reduced (Legends of the figures are regarded to the nano-grease containing such nanoparticle). Flash and fire points of the grease can determine the evaporation loss and humidity resistance of the grease.

\subsubsection{Evaporation loss}

Table 1 shows the evaporation loss rate in the base grease and modified greases with NPs. It is obvious from this table that adding NPs to the base grease decreased the evaporation loss rate of the grease and results indicate that CNFs had better performance in this regards with respect to the usage of other two NPs. The reduction trend of the parameter of evaporation loss in the modified grease with CNFs is

Table 1 Evaporation loss rate of nano-greases with different contents of NPs

\begin{tabular}{llll}
\hline $\begin{array}{l}\text { Weight per- } \\
\text { centages }\end{array}$ & \multicolumn{2}{l}{ Evaporation loss (\%) } \\
\cline { 2 - 4 } & $\begin{array}{l}\text { Nano-grease } \\
\text { with CNF }\end{array}$ & $\begin{array}{l}\text { Nano-grease } \\
\text { with C60 }\end{array}$ & $\begin{array}{l}\text { Nano-grease } \\
\text { with C-dot }\end{array}$ \\
\hline 0.0 & 1.2 & 1.2 & 1.2 \\
0.1 & 1.0 & 1.1 & 1.2 \\
0.2 & 1.0 & 1.0 & 1.1 \\
0.4 & 0.5 & 0.8 & 1.0 \\
0.6 & 0.5 & 0.5 & 1.0 \\
0.8 & 0.5 & 0.5 & 0.8 \\
1.0 & 0.4 & 0.5 & 0.8 \\
\hline
\end{tabular}

clear. Indeed, CNFs contributed to the better performance of the grease in terms of the evaporation loss by rate of $73 \%$. Evaporation loss is an important factor for evaluating the quality of greases and adding NPs to the base grease forms more stable lubrication layers in the structure of the grease. In fact, this property is closely dependent on the flash and fire points and humidity resistance of the grease, as it was mentioned in the previous section. Increasing the flash and fire points of the grease by utilizing NPs can be directly dependent on its evaporation loss reduction. Furthermore, humidity resistance reduction of modified greases containing NPs can also lead to their less evaporation loss rates.

\subsubsection{Water washout characteristics}

The rate of water washout for all nano-greases at the standard condition is reported in the Table 2 . Water washout property of lubricants can determine their humidity resistance because these two properties are inversely dependent to each other. Results indicate that raising of the NP content in the grease caused the increase in its water washout characteristic. In addition, CNFs led the improvement of humidity resistance by $50 \%$ (decrease in the water washout characteristic of CNF modified nanogrease by $50 \%$ ). NPs of C-dot and C60 contributed to the less improvement in this parameter than the use of CNFs. However, each of these NPs could be utilized to improve the structure of desired grease with respect to their applications and expectations.

\subsubsection{Extreme-pressure property}

Figure 12 shows the amount of welded point $(\mathrm{kg} f$ ) for the base grease and modified greases with different contents of NPs (according to the standard of ASTM D 2596). Results indicated that for the base grease at the loading of 315 $(\mathrm{kg} \mathrm{f})$, four balls are welded to each other. While for the

Table 2 Water washout characteristic for nano-greases at different contents of NPs

\begin{tabular}{llll}
\hline $\begin{array}{l}\text { Weight per- } \\
\text { centages }\end{array}$ & \multicolumn{3}{l}{ Amounts of washed nano-greases (\%) } \\
\cline { 2 - 4 } & $\begin{array}{l}\text { Nano-grease } \\
\text { with CNF }\end{array}$ & $\begin{array}{l}\text { Nano-grease } \\
\text { with C60 }\end{array}$ & $\begin{array}{l}\text { Nano-grease } \\
\text { with C-dot }\end{array}$ \\
\hline 0.0 & 4.3 & 4.3 & 4.3 \\
0.1 & 4.0 & 4.1 & 4.0 \\
0.2 & 3.5 & 3.8 & 4.1 \\
0.4 & 3.0 & 3.4 & 4.0 \\
0.6 & 2.4 & 3.0 & 4.0 \\
0.8 & 2.2 & 3.0 & 3.8 \\
1.0 & 2.1 & 3.0 & 3.8 \\
\hline
\end{tabular}


Fig. 12 Applied load for different nano-greases at the welding point

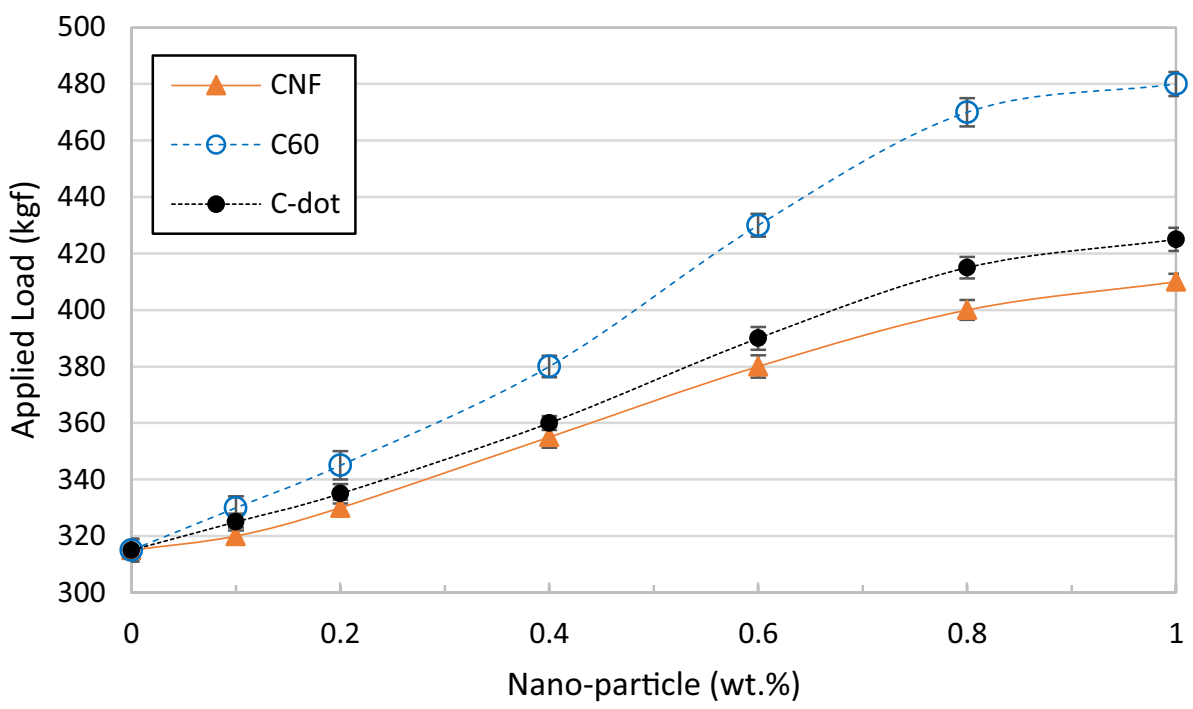

Table 3 Measurement of modified loading for the base grease

\begin{tabular}{llcc}
\hline $\begin{array}{l}\text { Applied load } \\
(\mathrm{L})(\mathrm{Kg})\end{array}$ & $\begin{array}{l}\text { Average scratch } \\
\text { diameter }(X)(\mathrm{mm})\end{array}$ & Factor of $L D_{\mathrm{h}}$ & $\begin{array}{l}\text { Modified load } \\
\left(\frac{L D_{h}}{\bar{X}}\right)_{(\mathrm{Kg} \mathrm{f})}\end{array}$ \\
\hline 80 & 0.37 & 30.08 & 79.16 \\
90 & 0.40 & 35.30 & 88.25 \\
100 & 0.42 & 40.50 & 96.43 \\
110 & 0.44 & 46.15 & 104.89 \\
126 & 0.46 & 55.20 & 120.00 \\
160 & 0.50 & 75.80 & 151.60 \\
200 & 0.57 & 102.20 & 179.30 \\
220 & 0.62 & 116.32 & 187.61 \\
250 & 0.68 & 137.50 & 202.21 \\
300 & 0.75 & 175.65 & 234.20 \\
315 & Welded & 187.10 & - \\
\hline
\end{tabular}

modified grease with $1 \%$ of $\mathrm{C} 60$, the loading was increased to 480 (kg f). In other words, this test clearly shows that C60 with its cage and spherical structure caused the improvement in performance of the grease to endure and transfer of applied loading at the high pressure. In addition, CNFs showed also to have this increasing trend in the loading. Modified loading and applied loading to reach the welding point (10 items to reach this point) for the base grease is shown in Table 3. As a result, the characteristic of abrasion-loading is 144.36 for the base grease. Figure 13 illustrates this characteristic for nano-greases with different weight percentages of NPs. It is obvious that raising the contents of NPs increased this characteristic and the best performance was obtained for the cases in which C60 NPs were used. This characteristic indicates the less abrasion with respect to the more loading. Furthermore,
Fig. 13 The effect of adding NPs to the base grease on their load wear index

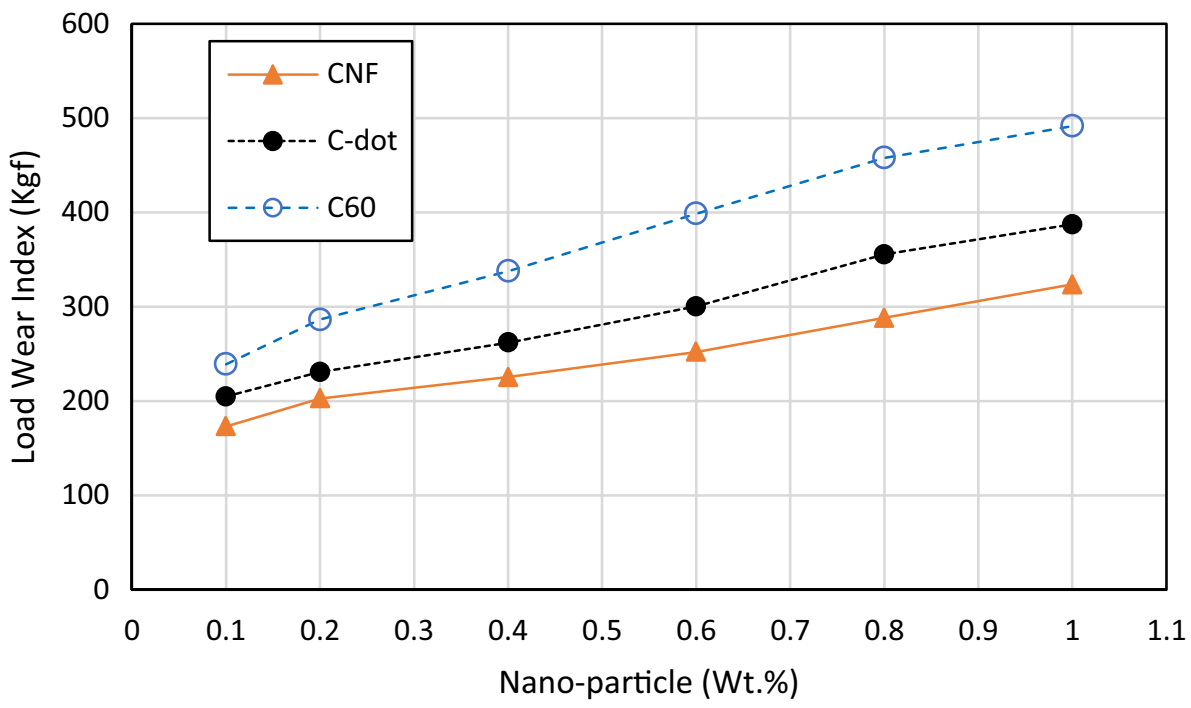

SN Applied Sciences 
strength of the oil film and ultimate capacity of the grease were both improved by using NPs. Continuity of the lubricating film could also be increased by the presence of NPs, resulting in the positive affect of the lubricating film strength (Legends of the figures are regarded to the nanogrease containing such nanoparticle).

\subsubsection{Resistance of nano-greases to fuel, water, and aqueous alcohol}

Prepared nano-greases were considered to apply in the industrial valves. As a result, their resistance to some solvents should be taken into consideration to have a better evaluation about their performances in these applications. For determining the resistance of nano-greases to fuel, a test fluid containing $60 \%$ of 2,2,4 Trimethylpentane, $25 \%$ of Toluene and $15 \%$ of Xylene was prepared and samples were immersed in that. Deterioration of samples in the test fluid were evaluated at $23 \pm 2{ }^{\circ} \mathrm{C}$ and in two cases of $7 \pm 0.5 \mathrm{~h}$ immersion in the solvent and $24 \mathrm{~h}$ of air drying. No swelling, blistering, cracking, loss of adhesion or other deterioration was observed in the resulting nano-greases in each of two cases.

Furthermore, the resistance of nano-grease samples to water was evaluated at $23 \pm 2{ }^{\circ} \mathrm{C}$ for $7 \pm 0.5 \mathrm{~h}$ and no disintegration of samples was detected in the nano-greases. Appearance of the water was also checked and no more than slight turbidity of the water was observed. An aqueous alcohol containing a 50/50 v/v mixture of distilled water and industrial methylated spirits was also prepared to investigate the resistance of nano-grease samples to it. The results from the visual examination of samples was also the same as the one in which water was used as the solvent at operating condition of $23 \pm 2{ }^{\circ} \mathrm{C}$ for $168 \pm 2 \mathrm{~h}$. As a consequence, all the prepared nano-greases were found to be resistant to the fuel, water, and aqueous alcohol.

\section{Conclusions}

Synthesis of C-dot NPs was successfully done by the hydrothermal method and nano-greases were fabricated by dispersing three different NPs (C60, CNF, C-dot), separately in the lithium based grease. Properties of the resulting nanogreases were investigated and compared with those of the base grease. Raising of the shear rate resulted in increase of the shear stress and decrease of the viscosity. Adding of NPs (up to $0.8 \mathrm{wt} \%$ for CNFs and $1 \mathrm{wt} \%$ for C60 and C-dot) to the base grease caused the increase in both of these parameters versus shear rate.

Penetration rate of conical piece in the grease (in the both worked and unworked mode) showed a descending trend in all the prepared nano-greases. The highest decrease was regarded to the nano-grease containing $0.8 \mathrm{wt} \%$ of CNF in the unworked mode and the one with $1 \mathrm{wt} \%$ of CNF in the worked mode by the rates of $27 \%$ and $28 \%$, respectively. In addition, raising the amount of NPs caused the increase in the dropping point of nano-greases. Modified nano-grease with $0.8 \mathrm{wt} \%$ of CNF devoted the highest amount of dropping point. The results of corrosion test indicated that the addition of all studied NPs to the lithium base grease did not cause any corrosion tracks. The highest amounts of flash and fire points were regarded to the modified grease with $0.4 \mathrm{wt} \%$ of CNF at $298^{\circ} \mathrm{C}$ and $305^{\circ} \mathrm{C}$, respectively.

Increasing the amount of NPs caused more humidity resistance in the grease and CNF modified grease had the maximum improvement in this parameter by the rate of $50 \%$. Adding $0.8 \mathrm{wt} \%$ and $1 \mathrm{wt} \%$. of CNFs to the base grease made them to be washed by about $2.2 \%$ and $2.1 \%$, respectively, as the best performances for water washout property among all of the synthesized nano-greases were found to be for the mentioned nano-greases. Therefore, addition of CNFs improved this parameter by $51 \%$. The extreme pressure was improved by the use of NPs. Nanogrease contained $1 \mathrm{wt} \%$ of C- 60 had the best performance in the extreme pressure property by about $52.4 \%$ and $240.7 \%$ for the improvement in applied loading at welding point and load-wear, respectively. All nano-grease samples were resistant to fuel, water, and aqueous alcohol at the specific time period and temperature. Through all the results, CNFs by the weight percentage of $(0.4-0.8) \%$ could be the best Nano additive to promote the properties of lithium based grease and the resulting nano-greases could be applied in industrial valves.

Acknowledgements Authors are grateful to the Fars Science and Technology Park for providing their equipped laboratories for them to successfully complete this work.

\section{Compliance with ethical standards}

Conflict of interest On behalf of all authors, the corresponding author states that there is no conflict of interest.

\section{References}

1. Mohamed A, Hamdy M, Bayoumi M, Osman T (2017) Synthesis and tribological properties of nanogrease. Ind Lubr Tribol Artic Inf 70:512-518

2. Am A, Khattab AB, Osman TA, Zaki MA (2013) Influence of nano grease composite on rheological behaviour. Int J Eng Res Appl 3:1126-1131

3. Lansdown AR (2013) Lubrication: a practical guide to lubricant selection. Elsevier, Amsterdam

4. Jones $M H$, Scott $D$ (1983) Industrial tribology: the practical aspects of friction, lubrication and wear. Elsevier, Amsterdam 
5. Bannister KE (1996) Lubrication for industry. Industrial Press Inc., New York City

6. Lugt PM (2012) Grease lubrication in rolling bearings. Wiley, Hoboken

7. Younes H, Christensen G, Groven L, Hong H, Smith P (2016) Three dimensional (3D) percolation network structure: key to form stable carbon nano grease. Rev Mex Trastor Aliment 14:375-382. https://doi.org/10.1016/j.jart.2016.09.002

8. Mota V, Ferreira LAÃ (2009) Influence of grease composition on rolling contact wear: experimental study. Tribol Int 42:569-574. https://doi.org/10.1016/j.triboint.2008.04.002

9. Dabiri E, Noori M, Zahmatkesh S (2018) Modeling and CFD simulation of volatile organic compounds removal from wastewater by membrane gas stripping using an electro-spun nanofiber membrane. J Water Process Eng. https://doi.org/10.1016/j. jwpe.2018.05.014

10. Sadeghalvaad M, Dabiri E, Zahmatkesh S, Afsharimoghadam $P(2018)$ Preparation and properties evaluation of nitrile rubber nanocomposites reinforced with organo-clay, $\mathrm{CaCO}_{3}$, and $\mathrm{SiO}_{2}$ nanofillers. Polym Bull. https://doi.org/10.1007/s0028 9-018-2583-8

11. Dabiri E, Bahrami F, Mohammadzadeh S (2018) Experimental investigation on turbulent convection heat transfer of SiC/W and $\mathrm{MgO} / \mathrm{W}$ nanofluids in a circular tube under constant heat flux boundary condition. J Therm Anal Calorim 131:2243-2259. https://doi.org/10.1007/s10973-017-6791-5

12. Zahmatkesh $\mathrm{S}$, Zebarjad SM, Bahrololoom ME, Dabiri E, Arab $\mathrm{SM}$ (2018) Synthesis of $\mathrm{ZnO} / \mathrm{In}_{2} \mathrm{O}_{3}$ composite nanofibers by co-electrospinning: a comprehensive parametric investigating the process. Ceram Int 45:2530-2541. https://doi.org/10.1016/j. ceramint.2018.10.184

13. Khorramdel H, Dabiri E, Tabrizi FF, Galehdari M (2019) Synthesis and characterization of graphene acid membrane with ultrafast and selective water transport channels. Sep Purif Technol 212:497-504. https://doi.org/10.1016/j.seppur.2018.11.044

14. Sadeghalvaad M, Sabbaghi S (2015) The preparation and rheological studies of the $\mathrm{TiO}_{2}$ /polyacrylamide nanofluid. J Nanofluids 4:435-441. https://doi.org/10.1166/jon.2015.1172

15. Sadeghalvaad M, Sabbaghi S (2017) Application of $\mathrm{TiO}_{2} /$ polyacrylamide core-shell nanocomposite as an additive for controlling rheological and filtration properties of water-based drilling fluid. J Nanofluids 6:205-212. https://doi.org/10.1166/ jon.2017.1318

16. Macwan DP, Dave PN (2011) A review on nano-TiO 2 sol-gel type syntheses and its applications. J Mater Sci 46:3669-3686. https ://doi.org/10.1007/s10853-011-5378-y

17. Bakunin VN, Suslov AY, Kuzmina GN, Parenago OP (2004) Synthesis and application of inorganic nanoparticles as lubricant components-a review. J Nanoparticle Res 6:273-284

18. Saito M, Tsuzuku T (2016) A review on graphite and hybrid nanomaterials as lubricant additives. https://doi.org/10.1088/1757899x/149/1/012201

19. Chang H, Lan C, Chen C, Kao M, Guo J (2014) Anti-wear and friction properties of nanoparticles as additives in the lithium grease. Int J Precis Eng Manuf 15:2059-2063. https://doi. org/10.1007/s12541-014-0563-y

20. Chang H, Kao M, Luo J, Lan C (2015) Synthesis and effect of nanogrease on tribological properties. Int J Precis Eng Manuf 16:1311-1316. https://doi.org/10.1007/s12541-015-0171-5

21. Bartz WJ (1972) Some investigations on the influence of particle size on the lubricating effectiveness of molybdenum disulfide. Tribol Trans 15:207-215

22. Chiñas-Castillo F, Spikes HA (2003) Mechanism of action of colloidal solid dispersions. J Tribol 125:552. https://doi. org/10.1115/1.1537752
23. Hu C, Bai M, Lv J, Liu H, Li X (2014) Molecular dynamics investigation of the effect of copper nanoparticle on the solid contact between friction surfaces. Appl Surf Sci 321:302-309. https:// doi.org/10.1016/j.apsusc.2014.10.006

24. Fan X, Xia Y, Wang L (2014) Multilayer graphene as a lubricating additive in bentone grease. Tribol Lett 55:455-464. https://doi. org/10.1007/s11249-014-0369-1

25. Tang Z, Li S (2014) A review of recent developments of friction modifiers for liquid lubricants (2007-present). Curr Opin Solid State Mater Sci 18:119-139. https://doi.org/10.1016/j.cossm s.2014.02.002

26. Lee C-G, Hwang Y-J, Choi Y-M, Lee J-K, Choi C, Oh J-M (2009) A study on the tribological characteristics of graphite nano lubricants. Int J Precis Eng Manuf 10:85-90. https://doi.org/10.1007/ s12541-009-0013-4

27. Chen J (2010) Tribological properties of polytetrafluoroethylene, nano-titanium dioxide, and nano-silicon dioxide as additives in mixed oil-based titanium complex grease. Tribol Lett 1:217-224. https://doi.org/10.1007/s11249-010-9593-5

28. Wu YY, Tsui WC, Liu TC (2007) Experimental analysis of tribological properties of lubricating oils with nanoparticle additives. Wear 262:819-825. https://doi.org/10.1016/j.wear.2006.08.021

29. Hong H, City R, Marquis FDS, City R, Waynick A, Antonio S (2007) Patent Application Publication (10) Pub No: US 2007/0158609 A1

30. Gara L, Zou Q (2012) Friction and Wear characteristics of waterbased $\mathrm{ZnO}$ and $\mathrm{Al}_{2} \mathrm{O}_{3}$ nanofluids. Tribol Trans 55:345-350. https ://doi.org/10.1080/10402004.2012.656879

31. Song X, Zheng S, Zhang J, Li W, Chen Q, Cao B (2012) Synthesis of monodispersed $\mathrm{ZnAl}_{2} \mathrm{O}_{4}$ nanoparticles and their tribology properties as lubricant additives. Mater Res Bull 47:4305-4310. https://doi.org/10.1016/j.materresbull.2012.09.013

32. Luo T, Wei X, Zhao H, Cai G, Zheng X (2014) Tribology properties of $\mathrm{Al}_{2} \mathrm{O}_{3} / \mathrm{TiO}_{2}$ nanocomposites as lubricant additives. Ceram Int 40:10103-10109. https://doi.org/10.1016/j.ceram int.2014.03.181

33. Lee K, Hwang Y, Cheong S, Kwon L, Kim S, Lee J (2009) Performance evaluation of nano-lubricants of fullerene nanoparticles in refrigeration mineral oil. Curr Appl Phys 9:e128-e131. https:// doi.org/10.1016/j.cap.2008.12.054

34. Martin JM, Ohmae N (2008) Nanolubricants. Wiley, Hoboken

35. Totten GE (2006) Handbook of lubrication and tribology. CRC Press, Boca Raton

36. Kotia A, Rajkhowa P, Rao GS, Ghosh SK (2018) Thermophysical and tribological properties of nanolubricants: a review. Heat Mass Transf 54:3493-3508. https://doi.org/10.1007/s0023 1-018-2351-1

37. Hemmat Esfe M, Afrand M, Yan W-M, Yarmand H, Toghraie D, Dahari M (2016) Effects of temperature and concentration on rheological behavior of MWCNTs/SiO 2 (20-80)-SAE40 hybrid nano-lubricant. Int Commun Heat Mass Transf 76:133-138. https ://doi.org/10.1016/j.icheatmasstransfer.2016.05.015

38. Ettefaghi E, Rashidi A, Ahmadi H, Mohtasebi SS, Pourkhalil M (2013) Thermal and rheological properties of oil-based nanofluids from different carbon nanostructures. Int Commun Heat Mass Transf 48:178-182. https://doi.org/10.1016/j.icheatmass transfer.2013.08.004

Publisher's Note Springer Nature remains neutral with regard to jurisdictional claims in published maps and institutional affiliations. 